\title{
A Rare Case of Amyotrophic Lateral Sclerosis With Asymmetrical Phrenic Nerve Lesion Presenting With Acute Respiratory Failure as an Initial Manifestation
}

\author{
Rubén Blanco ${ }^{1}$, Jessie Pichardo ${ }^{2}$, Hassan Abdullah ${ }^{3,4}$
}

1. Neurology, Pontificia Universidad Católica Madre y Maestra, Santiago, DOM 2. Medicine, Pontificia Universidad Católica Madre y Maestra, Santiago, DOM 3. Neurology, University of Alabama, Birmingham, USA 4. Medicine, Nishtar Medical University, Multan, PAK

Corresponding author: Hassan Abdullah, dochassanabdullah@gmail.com

\begin{abstract}
Amyotrophic lateral sclerosis (ALS) is a progressive neurodegenerative disorder that causes muscle weakness, disability, and eventually, death. Respiratory failure is the leading cause of death in ALS. It is common in the advanced stages of the disease. However, acute respiratory failure is a presenting symptom in only a small number of patients, such as in our case. Here, we present the case of a 54-year-old woman with ALS presenting with respiratory failure due to unilateral diaphragm paralysis as the first manifestation. Although rare, respiratory muscle function failure can be the first symptom of motor neuron disease. Therefore, a motor neuron disease such as ALS, which leads to respiratory muscle weakness and diaphragm paralysis, should be considered in cases of unexplained acute respiratory failure.
\end{abstract}

Review began 12/24/2020 Review ended 01/02/2021 Published 01/07/2021

\section{() Copyright 2021}

Blanco et al. This is an open access article distributed under the terms of the Creative Commons Attribution License CC-BY 4.0., which permits unrestricted use, distribution, and reproduction in any medium, provided the original author and source are credited.
Categories: Internal Medicine, Neurology, Pulmonology

Keywords: motor neuron disease, acute hypoxemic respiratory failure, amyotrophic lateral sclerosis, phrenic nerve, upper motor neuron lesion, lower motor neuron lesion

\section{Introduction}

Amyotrophic lateral sclerosis (ALS), also known as Lou Gehrig's disease, is a progressive neuromuscular condition characterized by weakness, muscle wasting, fasciculations, and increased reflexes [1]. It is the most common degenerative disease of the motor neuron system. There appears to be a gender predilection for ALS with higher propensity for males [1]. ALS has an annual incidence of 1.75/100,000 person/years, and it is believed to be the same worldwide, most of which is sporadic [2].

Clinical features of ALS are the combination of both upper and lower motor neuron lesion signs and symptoms. Initially, it manifests as problems with dexterity or gait resulting from muscle weakness. Later, patients develop severe, progressive muscular weakness and other symptoms caused by loss of function in both upper and lower motor neurons during the disease. In advanced stages, diaphragm palsy is common and is a primary cause of morbidity [1]. Nevertheless, acute respiratory failure as a presenting symptom is rare.

\section{Case Presentation}

We report the case of a 54-year-old woman with ALS presenting with respiratory failure requiring immediate mechanical ventilation (Figure 1). 


\section{Cureus}

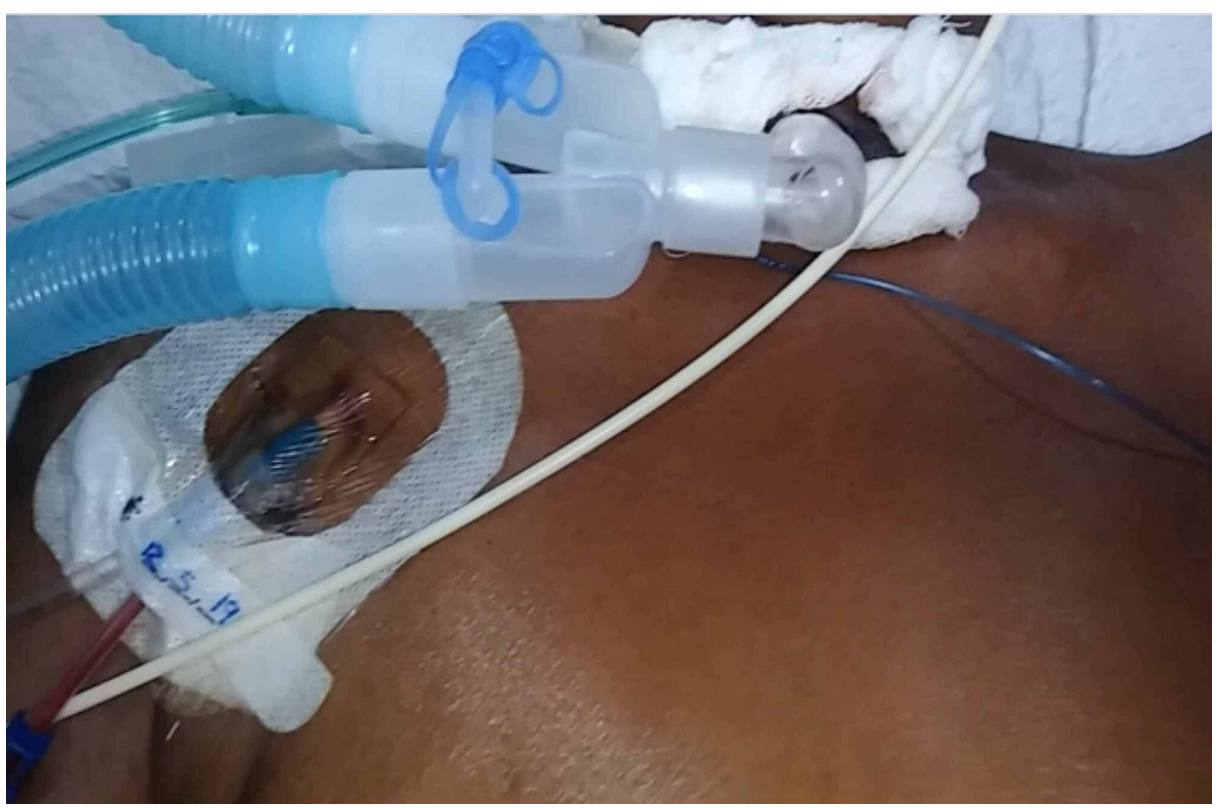

FIGURE 1: Patient on mechanical ventilation.

Apart from having diabetes mellitus, she had a non-significant past medical history. Before this episode, there was no history of body weakness, speech dysfluency, respiratory distress, or sensory deficits. Her neurological examination revealed dysarthria, paraparesis, and distal atrophy. She also had fasciculations, and her plantar reflexes were extensor bilaterally. The sensory system was intact.

After hospitalization, weaning mechanical ventilation attempts were ineffective as the patient rapidly entered periods of hypoxemia (desaturation). At that time, the doctors on the medicine floor consulted the neurology team. The neurology team initially thought that the patient might have myasthenia gravis (weakness and fatigue of voluntary muscles), but her neurology examination documented distal muscle atrophy (Figure 2).

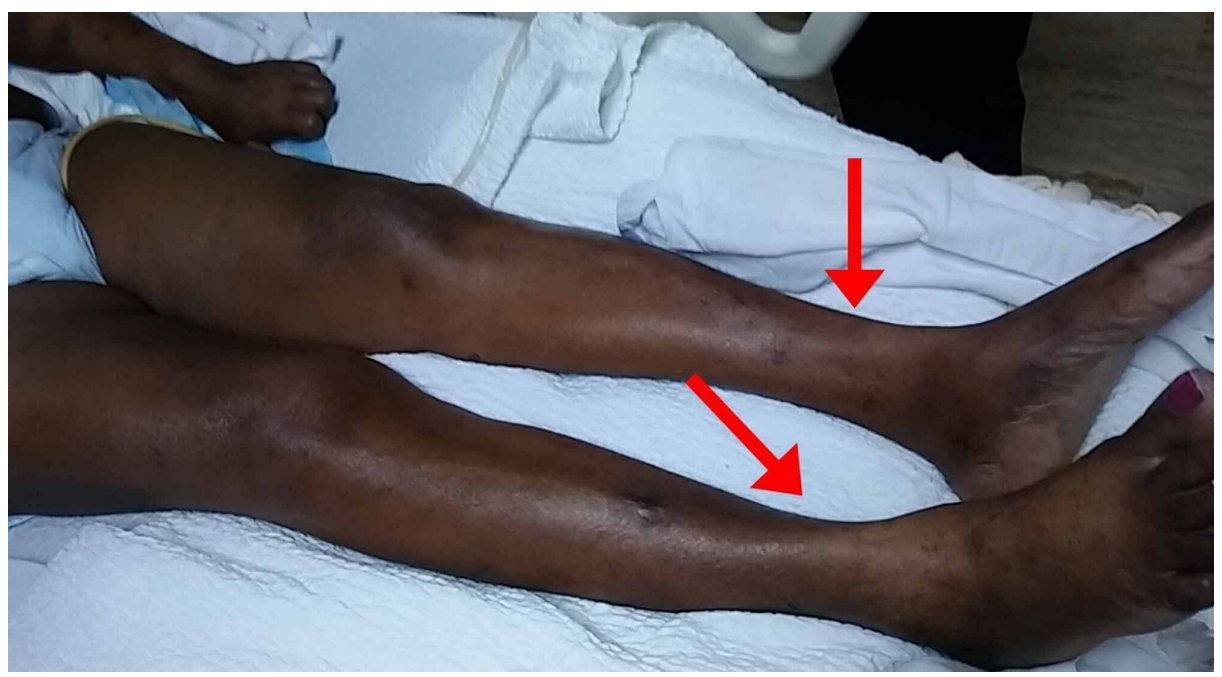

FIGURE 2: Distal atrophy of the leg muscles bilaterally.

Hence, we ordered an electroneuromyography for the patient that showed axonal loss without motor conduction blocks, with preserved sensory responses (Table 1). 


\begin{tabular}{|c|c|c|c|c|c|c|c|c|c|}
\hline \multirow[t]{2}{*}{ Nerve } & Muscle & Latency & Amplitude & Rel Amp & Duration & Segments & Distance & Lat Diff & Velocity \\
\hline & & Ms & $\mathrm{mV}$ & $\%$ & $\mathrm{~ms}$ & & $\mathrm{Cm}$ & $\mathrm{ms}$ & $\mathrm{m} / \mathrm{s}$ \\
\hline \multicolumn{10}{|l|}{$R$ median - APB } \\
\hline Wrist & APB & 3.68 & 2.9 & 100 & 5.63 & Wrist - APB & 7 & & \\
\hline Elbow & APB & 11.04 & 2.7 & 94.7 & 5.57 & Elbow - Wrist & 25 & 5.36 & 47 \\
\hline \multicolumn{10}{|l|}{ L median - APB } \\
\hline Wrist & APB & 3.84 & 0.2 & 100 & 12.71 & Wrist - APB & 7 & & \\
\hline Elbow & APB & 10.05 & 0.2 & 100 & 65.73 & Elbow - Wrist & 25 & 5.21 & 48 \\
\hline \multicolumn{10}{|l|}{ R ulnar - ADM } \\
\hline Wrist & ADM & 3.13 & 3.4 & 100 & 6.20 & Wrist - ADM & 7 & & \\
\hline B. Elbow & ADM & 8.13 & 3.4 & 101 & 6.09 & B. Elbow - Wrist & 25 & 5.00 & 50 \\
\hline A. Elbow & ADM & 11.25 & 3.2 & 93 & 5.99 & A. Elbow - B. Elbow & 16 & 3.13 & 51 \\
\hline Axilla & ADM & 13.59 & 2.8 & 87.1 & 6.20 & Axilla - A. Elbow & 11 & 2.34 & 47 \\
\hline Erb's Pt & ADM & 15.05 & 2.6 & 92.8 & 6.20 & Erb's Pt - Axilla & 35 & 1.46 & 240 \\
\hline \multicolumn{10}{|l|}{ R ulnar - ADM (1) } \\
\hline Wrist & ADM & 3.13 & 4.1 & 100 & 6.15 & Wrist - ADM & 7 & & \\
\hline Post exercise & ADM & 3.65 & 3.8 & 92.2 & 5.47 & Post exercise - Wrist & & 0.52 & \\
\hline \multicolumn{10}{|c|}{$\mathrm{R}$ deep peroneal - EDB } \\
\hline Ankle & EDB & 3.44 & 2.5 & 100 & 4.64 & Ankle - EDB & 8 & & \\
\hline Fib Head & EDB & 10.57 & 2.2 & 81.5 & 4.58 & Fib head - ankle & 35 & 7.14 & 49 \\
\hline Knee & EDB & 11.82 & 2.2 & 102 & 4.19 & Knee- fib head & 10 & 1.25 & 80 \\
\hline \multicolumn{10}{|c|}{ R tibial (knee) - AH } \\
\hline Ankle & AH & 5.10 & 3.9 & 100 & 8.13 & Ankle-AH & 8 & & \\
\hline Knee & AH & 14.74 & 3.6 & 90.7 & 7.66 & Knee-Ankle & 42 & 9.64 & 44 \\
\hline \multicolumn{10}{|c|}{ L tibial (knee) - AH } \\
\hline Ankie & $\mathrm{AH}$ & 5.94 & 3.7 & 100 & 7.34 & Ankle-AH & 8 & & \\
\hline Knee & $\mathrm{AH}$ & 17.60 & 3.5 & 95.2 & 10.83 & Knee-Ankle & 42 & 11.67 & 36 \\
\hline \multicolumn{10}{|c|}{ L deep peroneal - EDB } \\
\hline Ankle & EDB & 5.10 & 0.5 & 100 & 3.91 & Popliteal fossa - Gastronec & 8 & & \\
\hline Fib H & EDB & 13.59 & 0.4 & 75.2 & 8.65 & Knee - Popliteal fossa & 35 & 8.49 & 41 \\
\hline Knee & EDB & 15.52 & 0.5 & 113 & 5.52 & Ankle - ADQ & & & \\
\hline
\end{tabular}

\section{TABLE 1: Motor nerve conduction studies.}

ADM, abductor digiti minimi; ADQP, abductor digiti quinti pedis; AH, adductor hallucis; APB, abductor pollicis brevis; EDB, extensor digitorum brevis; L, left; R, right

The repetitive nerve stimulation was normal at abductor digiti minimi bilaterally that ruled out any neuromuscular junction dysfunction such as myasthenia gravis (Figure 3). 


\section{Cureus}

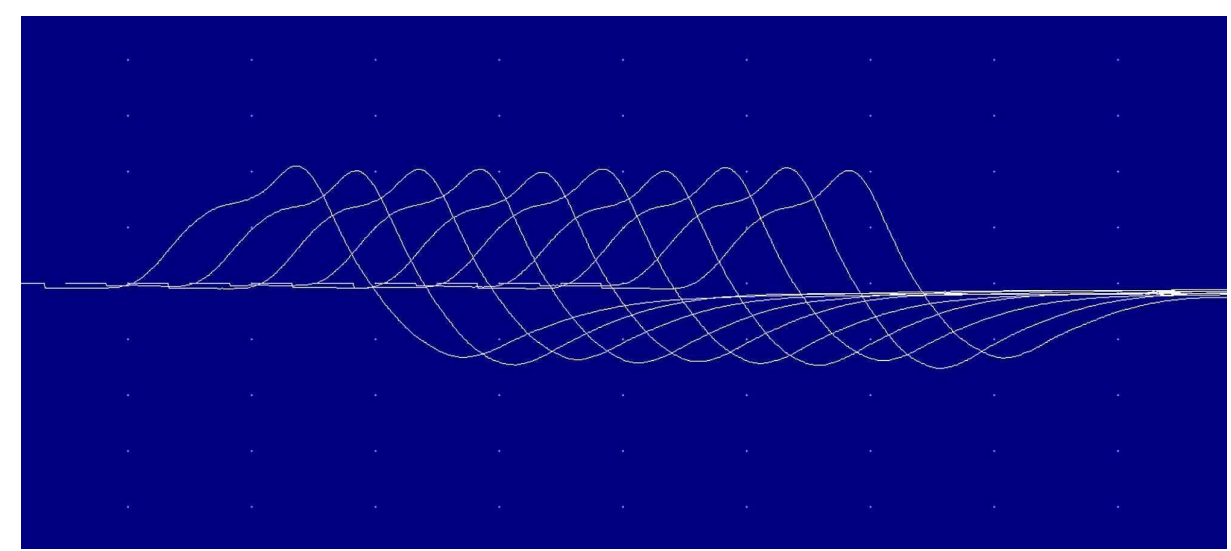

FIGURE 3: Repetitive nerve stimulation on right ADM.

ADM, abductor digiti minimi

The conduction velocity performed in the phrenic nerves bilaterally showed an abnormal left-sided response (Figure 4).

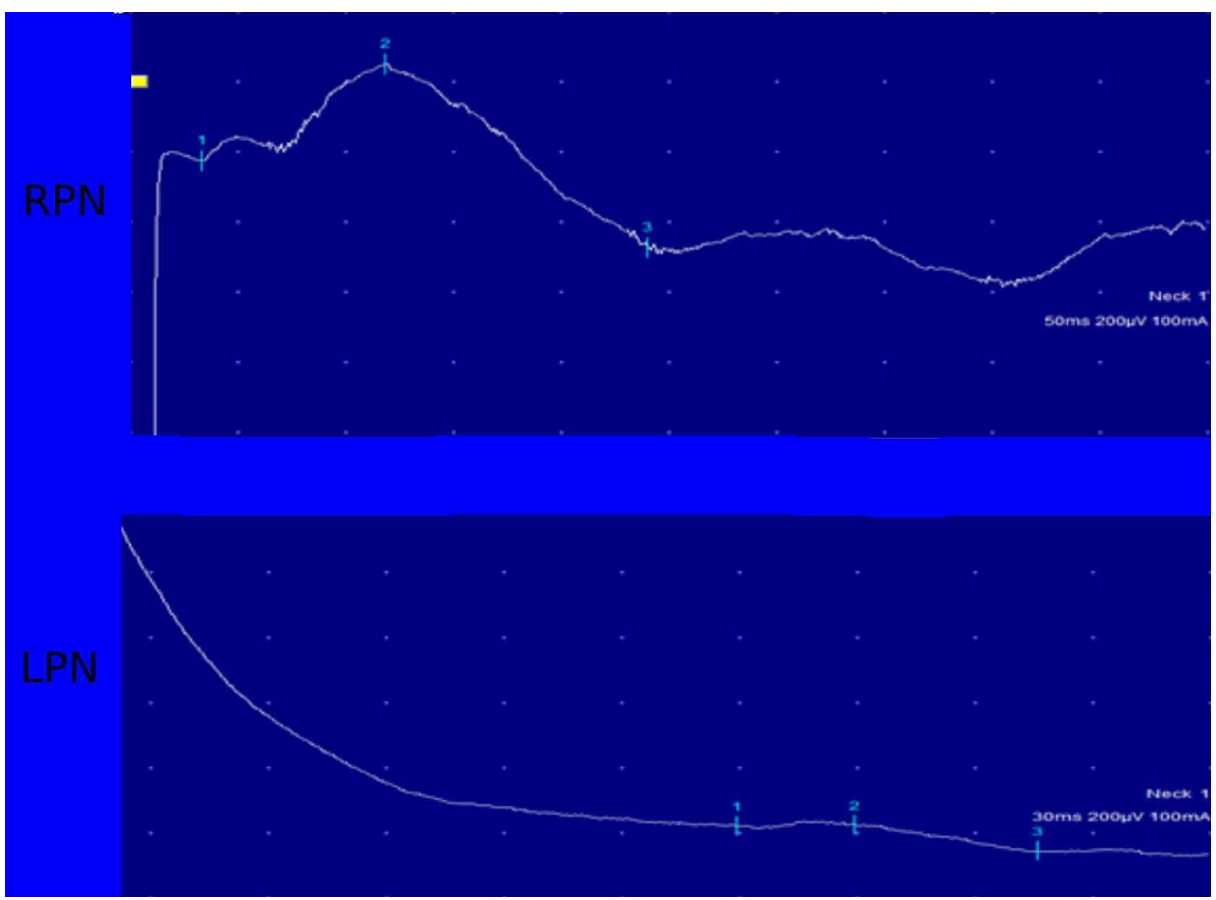

FIGURE 4: Electroneuromyography of the right and left phrenic nerves.

LPN, left phrenic nerve; RPN, right phrenic nerve

The left phrenic nerve response had increased latency and decreased amplitude (Table 2). 


\section{Cureus}

\begin{tabular}{|c|c|c|}
\hline Stimulus site & Lat (ms) & Amp (mV) \\
\hline Left phrenic nerve & 17.92 & 0.1 \\
\hline Right phrenic nerve & 7.25 & 0.5 \\
\hline
\end{tabular}

TABLE 2: Amplitude and latency of the right and left phrenic nerves.

The needle examination revealed signs of denervation, as shown in Figure $5 \mathrm{~A}$, in all the muscle territories evaluated, including the bulbar area, signs of chronic reinnervation, and reduced discrete motor unit recruitment pattern (Figure $5 B$ ).

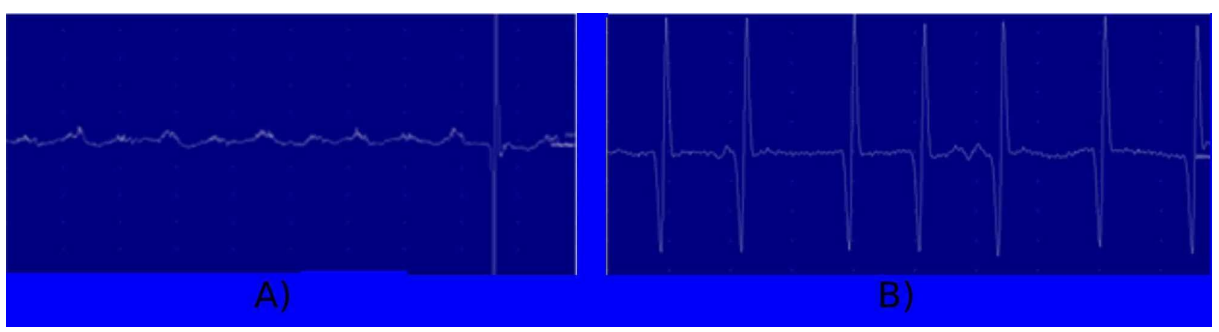

FIGURE 5: Fasciculations as a sign of denervation (A), and discrete recruitment pattern in deltoid muscle (B).

These results were compatible with a motor neuron degenerative syndrome, that is, ALS, along with a concomitant left phrenic nerve lesion. Hence, the patient was diagnosed with ALS accompanied with a partial peripheral lesion of the phrenic nerve.

We did the test of weaning her off from mechanical ventilation, and 30 seconds to a minute later, her saturation reduced to $93 \%$ (Figure 6).
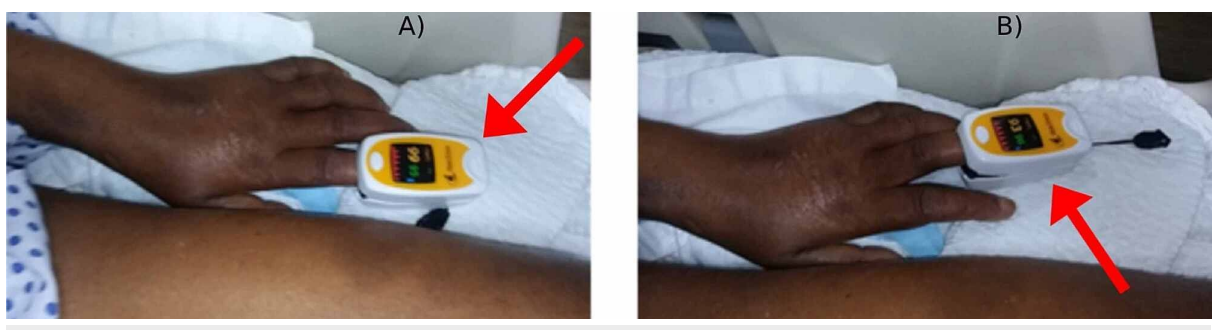

FIGURE 6: (A) Patient on mechanical ventilation (99\% saturation). (B) One minute after weaning from the ventilator ( $93 \%$ saturation).

This confirmed the phrenic nerve lesion. Any mechanical cause of the phrenic nerve lesion was ruled out on a chest X-ray and chest computed tomography. We concluded that she was desaturating due to paralysis of the left hemidiaphragm and the rib cage muscle weakness secondary to the underlying disorder.

\section{Discussion}

ALS is caused by the progressive loss of motor neurons, leading to weakness and subsequent paralysis of the face, bulbar, and extremity muscles, including the diaphragm [3].

Respiratory failure has been mostly described in the late stages of the disease; however, our patient revealed an atypical presentation in isolation in the acute phase, as described in other studies [4]. Czapliński et al. reported a case presenting respiratory failure as an early manifestation of ALS [5]. Similar to our case, the patient had diaphragmatic paralysis, but it was bilateral instead of unilateral. Crescimanno et al. also noted early and rapidly progressing respiratory failure in a patient with ALS [6].

Patients who develop acute respiratory failure may have an underlying comorbid condition, for example, 
chronic obstructive pulmonary disease (COPD). Fromm et al. [7] and Parhad et al. [8] observed acute respiratory failure as a sole initial manifestation in patients later diagnosed with ALS. But these patients had COPD as a comorbidity. Similarly, Al-Shaikh et al. reported a case with similar signs and symptoms, with pneumothorax as a background illness [9].

When respiratory disturbance is the sole manifestation, more significant denervation signs have been described in the diaphragmatic muscles than in the rest of the skeletal muscles [4]. The most common cause of diaphragmatic paralysis in adults is trauma to the cervical spine, followed by neuromuscular diseases such as myasthenia gravis, myopathies, dystrophies, and medullary anterior horn disease, as in the present case [10].

\section{Conclusions}

ALS is a complex disease in which patients are highly dependent on medical care. Acute respiratory failure can be the first symptom of motor neuron disease. Therefore, in cases of unexplained acute respiratory failure or when there is prolonged intubation for no apparent reason, a motor neuron disease such as ALS should be considered. ALS can lead to respiratory muscle weakness and diaphragm paralysis. Respiratory evaluation and continuous monitoring can prolong survival and improve the quality of respiratory care for patients. The initial electrophysiological evaluation continues to be the best access and accurate diagnostic tool when a neuromuscular disorder is suspected as the genesis of acute dyspnea.

\section{Additional Information \\ Disclosures}

Human subjects: Consent was obtained by all participants in this study. Conflicts of interest: In compliance with the ICMJE uniform disclosure form, all authors declare the following: Payment/services info: All authors have declared that no financial support was received from any organization for the submitted work. Financial relationships: All authors have declared that they have no financial relationships at present or within the previous three years with any organizations that might have an interest in the submitted work. Other relationships: All authors have declared that there are no other relationships or activities that could appear to have influenced the submitted work.

\section{References}

1. Walling AD: Amyotrophic lateral sclerosis: Lou Gehrig's disease. Am Fam Physician. 1999, 59:1489-1496.

2. Benoît M, Farid B, Giancarlo L, et al.: Variation in worldwide incidence of amyotrophic lateral sclerosis: a meta-analysis. Int J Epidemiol. 2017, 46:57-74. 10.1093/ije/dyw061

3. Sanjuán-López P, Valiño-López P, Ricoy-Gabaldón J, Verea-Hernando H: Amyotrophic lateral sclerosis: impact of pulmonary follow-up and mechanical ventilation on survival. A study of 114 cases. Arch Bronconeumol. 2014, 50:509-513. 10.1016/j.arbres.2014.04.010

4. Tateno F, Sakakibara R, Kawashima K, Kishi M, Tsuyusaki Y, Aiba Y, Ogata T: Amyotrophic lateral sclerosis presenting respiratory failure as the sole initial manifestation. Case Rep Neurol. 2014, 6:213-216. $10.1159 / 000366191$

5. Czapliński A, Strobel W, Gobbi C, Steck AJ, Fuhr P, Leppert D: Respiratory failure due to bilateral diaphragm palsy as an early manifestation of ALS. Med Sci Monit. 2003 , 9:34-36.

6. Crescimanno G, Romano M, Spataro R, La Bella V, Marrone O: Early and rapidly progressing respiratory failure in a patient with amyotrophic lateral sclerosis: when FVC\% is misleading. Neurol Sci. 2019, 40:421422. 10.1007/s10072-018-3590-0

7. Fromm GB, Wisdom PJ, Block AJ: Amyotrophic lateral sclerosis presenting with respiratory failure. Diaphragmatic paralysis and dependence on mechanical ventilation in two patients. Chest. 1977, 71:612614. 10.1378/chest.71.5.612

8. Parhad IM, Arthur WC, Kevin D, Barron, Sheldon BS: Diaphragmatic paralysis in motor neuron disease. Report of two cases and a review of the literature. Neurology. 1978, 28:18. 10.1212/wnl.28.1.18

9. Al-Shaikh B, Kinnear W, Higenbottam TW, Smith HS, Shneerson JM, Wilkinson I: Motor neuron disease presenting as respiratory failure. Br Med J (Clin Res Ed). 1986, 292:1325-1326. 10.1136/bmj.292.6531.1325

10. Kokatnur L, Rudrappa M: Diaphragmatic palsy. Diseases. 2018, 6:16. 10.3390/diseases6010016 